Article

\title{
Study on Antibacterial and Quorum-Sensing Inhibition Activities of Cinnamomum camphora Leaf Essential Oil
}

\author{
Wenting Wang ${ }^{1}$, Dongxiang $\mathrm{Li}^{1}{ }^{1}$, Xiaoqin Huang ${ }^{1}$, Huixiang Yang ${ }^{1}$, Ziwen Qiu ${ }^{1}$, Liting Zou ${ }^{1}$, \\ Qin Liang ${ }^{1}$, Yu Shi ${ }^{1}$, Yingxiang $\mathrm{Wu}^{2}$, Shaohua $\mathrm{Wu}^{1, *}$, Chao Yang ${ }^{1, *}$ and Yongyu $\mathrm{Li}^{1, *}$ \\ 1 College of Horticulture, Fujian Agriculture and Forestry University, Fuzhou 350002, China; \\ wangwtsci@163.com (W.W.); dongxiang_li@163.com (D.L.); 13305929270@163.com (X.H.); \\ 13023832839@163.com (H.Y.); Qzw1996111@outlook.com (Z.Q.); Mizai_8zone@163.com (L.Z.); \\ liangqin_1130@163.com (Q.L.); sychiyu@163.com (Y.S.) \\ 2 Qingyuan Agricultural Science and Technology Extension Service Center, Qingyuan 511518, China; \\ wuyingxing8501@163.com \\ * Correspondence: wsh6677@hotmail.com (S.W.); yycc32@126.com (C.Y.); lilin3182@163.com (Y.L)
}

Received: 24 September 2019; Accepted: 19 October 2019; Published: 21 October 2019

\begin{abstract}
Many essential oils (EOs) regulate the quorum-sensing (QS) system of pathogens and inhibit the virulence expression. Interference with QS can potentially reduce bacterial multidrug resistance and aid the biological control of bacterial disease. In the present work, the antibacterial and anti-QS activities of Cinnamomum camphora leaf EO were investigated. A total of 23 chemical components with relative levels $\geq 0.11 \%$, including a large number of terpene compounds, were identified in C. camphora leaf EO by gas chromatography-mass spectrometry (GC-MS). The principal component was linalool, followed by eucalyptol, with relative levels of $51.57 \%$ and $22.07 \%$, respectively. The minimum inhibitory concentration (MIC) and antibacterial activity of C. camphora EO were examined, and P. aeruginosa and E. coli ATCC25922 showed the highest and lowest sensitivity to C. camphora EO, respectively. Tests of QS inhibitory activity revealed that $C$. camphora EO significantly decreased the production of violacein and biofilm biomass in $C$. violaceum, with the maximum inhibition rates of $63 \%$ and $77.64 \%$, respectively, and inhibited the biofilm formation and swarming movement, independent of affecting the growth of $C$. violaceum. Addition of $C$. camphora EO also resulted in downregulation of the expression of the acyl-homoserine lactones (AHL) synthesis gene (cviI) and transcription regulator (cviR), and inhibited the expression of QS-regulated virulence genes, including vioA, vioB, vioC, vioD, vioE, las A, lasB, pilE3, and hmsHNFR. Collectively, the prominent antibacterial activity and anti-QS activities clearly support that $C$. camphora EO acts as a potential antibacterial agent and QS inhibitor in the prevention of bacterial contamination.
\end{abstract}

Keywords: Cinnamomum camphora leaf essential oil; gas chromatography-mass spectrometry (GC-MS); antibacterial activity; Chomobacterium violaceum ATCC31532; quorum sensing (QS)

\section{Introduction}

In recent years, antibiotics and antimicrobial agents have been widely used for the prevention and control of bacterial diseases. Traditional antimicrobial agents inhibit and kill bacteria by interfering with their biochemical metabolism as well as by affecting their structure and functions [1]. Bacteria rapidly mutate under selective pressure, which results in rapid increases in drug-resistant bacteria and leads to many difficulties in the prevention and treatment of bacterial diseases. Therefore, the discovery of different novel therapies to treat or decrease cases of bacterial infections is urgently required. Inhibition of quorum sensing (QS) may be a suitable solution. Bacterial 
quorum sensing is a regulatory mechanism in bacterial colony communications whereby bacteria produce and secrete specific signal molecules and perceive the changes in the bacterial quantity in their surrounding environment through the changes in the concentration of the signal molecule (autoinducer, AI). QS endows a large number of individual bacteria with the ability to coexpress certain genes under specific conditions. Bacterial activities, including the release of pathogenic factors, the formation of biofilms, fluorescence, the formation of spores, the production of antibiotics, and DNA transcription, can be regulated by QS [2]. Studies have shown that quorum sensing (QS) is capable of regulating the activities of protein, fat, pectin, chitosan, and other decomposing enzymes related to pathogenic bacteria, and different types of QS signal molecules have also been detected in diseased tissue [3]. To date, a few antimicrobial agents with broad-spectrum antimicrobial activity have been shown to have QS inhibitory effects at sub minimal inhibitory concentration (sub-MIC) $[4,5]$. Many QS inhibitors (QSIs) of plant origin can inhibit the QS activities and reduce the pathogenicity of pathogens without inhibiting bacterial growth and these QSIs have the advantage of both not inducing drug resistance and being capable of preventing and controlling bacterial contamination [6]. Therefore, plant natural products could be the useful biological control agents targeted at bacterial QS networks. Chromobacterium violaceum and Pseudomonas aeruginosa PAO1 are well-known bioindicators used to identify substances that can block the QS mechanism $[7,8]$.

Studies have shown that plant essential oils (EOs) can be used as QSIs to control bacterial diseases due to their broad and prominent antibacterial properties [9]. In addition, plant-derived EOs are the safe alternative to chemical antimicrobial agents. Husain et al. [10] found that Mentha piperita EO interfered with the production of AHL signal molecules and the biofilm formation in gram-negative bacteria and showed significant QSI activity. A study by Vattem et al. [11] hypothesized that the mechanism by which oregano essential oil reduces violacein may be associated with its principal component, carvacrol, which may inhibit the expression of AHL synthesis genes. Eugenol, the principal component of Cinnamomum verum EO, in combination with antibiotics, synergistically inhibited the QS activity of Escherichia coli [12]. The curcumin in Curcuma longa inhibited the formation of bacterial biofilms and QS-mediated physiological behaviors [13]. Trans-cinnamaldehyde inhibited AHL signal molecule synthesis by interacting with the substrates of the signal molecule synthase and thus inhibited the QS activity of $P$. aeruginosa [14].

Cinnamomum camphora, a species of evergreen trees in the Lauraceae family, is a primary tree species in the subtropical broad-leaved forest and is a commonly used aromatic tree species for afforestation in China. The roots, bark, leaf, and fruits of C. camphora can be used for medicinal purposes and are rich in EOs with antibacterial, anti-inflammatory, and insect-repellent properties [15]. Notably, C. camphora EO is the primary raw material for camphor and borneol in the medical industry. The antimicrobial activity of C. camphora has been studied recently, but its anti-QS ability has never been described, thus we identified the components of C. camphora EO and demonstrated antibacterial activity and QS inhibitory activity. We provided theoretical and experimental support for the development of C. camphora EO into a potential biological control agent.

\section{Results}

\subsection{Analysis of the Components in C. camphora EO}

The yield of EO extracted from C. camphora leaf by steam distillation was $1.4 \%$. A total ion flow chromatogram of the C. camphora EO analyzed by gas chromatography-mass spectrometry (GC-MS) is shown in Figure 1. Correlations of the peak area normalization results with the mass spectrometry database were performed to qualitatively and quantitatively analyze the components of the EO. Table 1 shows that 23 components with relative levels $\geq 0.11 \%$ were identified from the C. camphora EO, accounting for $97.55 \%$ of the total content. The C. camphora EO primarily contained linalool, eucalyptol, sabinene, $\alpha$-terpineol, caryophyllene, nerolidol, $\alpha$-pinene, camphor, and $\beta$-pinene, which accounted 
for more than $90 \%$ of the total content. The principal component was linalool (51.57\%), followed by eucalyptol $(22.07 \%)$, which indicated that the C. camphora in this study belonged to the linalool type.

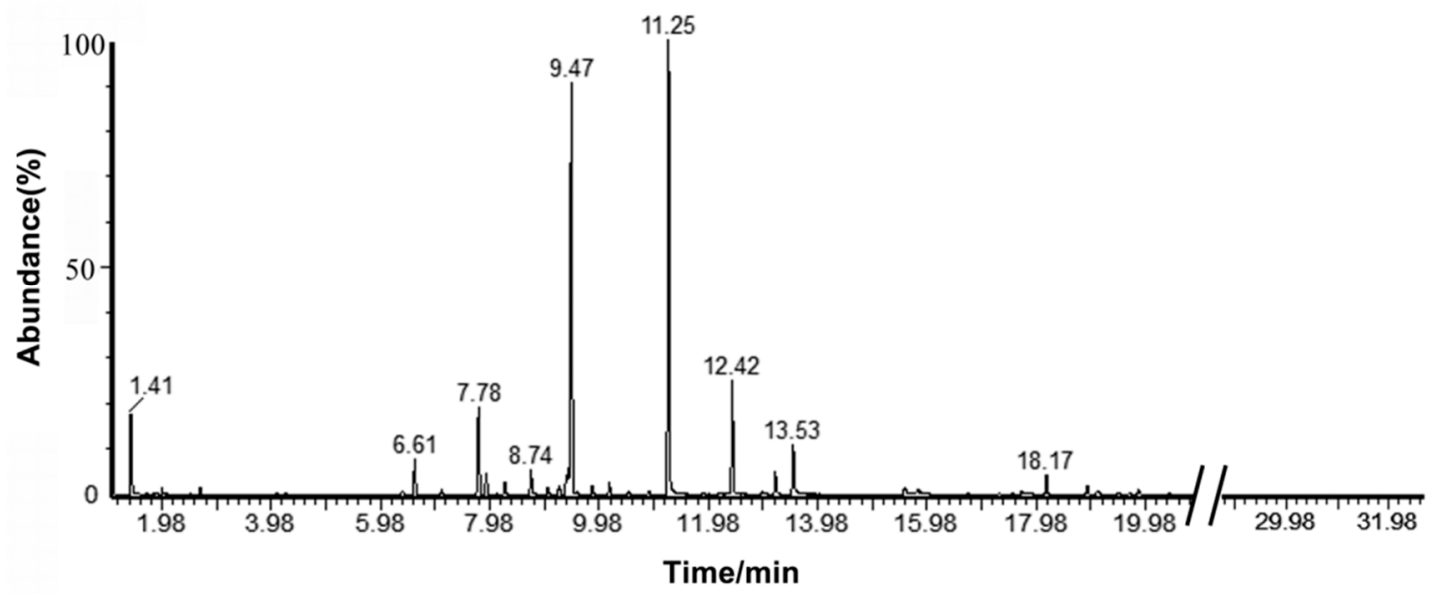

Figure 1. The GC-MS total ion chromatogram of C. camphora EO.

Table 1. Chemical composition of C. camphora EO.

\begin{tabular}{ccccccc}
\hline NO. & Compound Name & $\begin{array}{c}\text { Molecular } \\
\text { Formula }\end{array}$ & $\begin{array}{c}\text { Molecular } \\
\text { Weight }\end{array}$ & $\begin{array}{c}\text { Relative } \\
\text { Content }\end{array}$ & $\begin{array}{c}\text { Retention } \\
\text { Time/min }\end{array}$ & $\begin{array}{c}\text { Retention } \\
\text { Index }\end{array}$ \\
\hline 1 & Linalool & $\mathrm{C}_{10} \mathrm{H}_{18} \mathrm{O}$ & 154.25 & $51.57 \%$ & 11.25 & 1021 \\
2 & Cineole & $\mathrm{C}_{10} \mathrm{H}_{18} \mathrm{O}$ & 154.25 & $22.07 \%$ & 9.47 & 981 \\
3 & Sabenene & $\mathrm{C}_{10} \mathrm{H}_{16}$ & 136.23 & $5.38 \%$ & 12.42 & 1046 \\
4 & $\alpha$-Terpineol & $\mathrm{C}_{10} \mathrm{H}_{18} \mathrm{O}$ & 154.25 & $3.81 \%$ & 7.78 & 939 \\
5 & Caryophyllene & $\mathrm{C}_{15} \mathrm{H}_{24}$ & 204.35 & $2.77 \%$ & 13.54 & 1069 \\
6 & Nerolidol & $\mathrm{C}_{15} \mathrm{H}_{26} \mathrm{O}$ & 222.37 & $1.97 \%$ & 6.61 & 911 \\
7 & 1 - $\alpha$-Pinene & $\mathrm{C}_{10} \mathrm{H}_{16}$ & 136.23 & $1.68 \%$ & 8.74 & 963 \\
8 & camphor & $\mathrm{C}_{10} \mathrm{H}_{16} \mathrm{O}$ & 152.23 & $1.42 \%$ & 7.92 & 943 \\
9 & B-Pinene & $\mathrm{C}_{10} \mathrm{H}_{16}$ & 136.23 & $1.12 \%$ & 9.43 & 980 \\
10 & Terpineol & $\mathrm{C}_{10} \mathrm{H}_{18} \mathrm{O}$ & 154.25 & $0.89 \%$ & 13.20 & 1062 \\
11 & Methyleugenol & $\mathrm{C}_{11} \mathrm{H}_{14} \mathrm{O}_{2}$ & 178.23 & $0.83 \%$ & 18.17 & 1167 \\
12 & a-Humulene & $\mathrm{C}_{15} \mathrm{H}_{24}$ & 204.35 & $0.76 \%$ & 9.39 & 986 \\
13 & Myrcene & $\mathrm{C}_{10} \mathrm{H}_{16}$ & 136.23 & $0.56 \%$ & 8.26 & 951 \\
14 & Caryophyllene oxide & $\mathrm{C}_{15} \mathrm{H}_{24} \mathrm{O}$ & 220.35 & $0.45 \%$ & 10.18 & 998 \\
15 & g-Terpinene & $\mathrm{C}_{10} \mathrm{H}_{16}$ & 136.23 & $0.40 \%$ & 15.81 & 1117 \\
16 & $\alpha$-Phellandrene & $\mathrm{C}_{10} \mathrm{H}_{16}$ & 136.23 & $0.35 \%$ & 18.91 & 1182 \\
17 & Limonene & $\mathrm{C}_{10} \mathrm{H}_{16}$ & 136.23 & $0.32 \%$ & 17.71 & 1157 \\
18 & Elixene & $\mathrm{C}_{15} \mathrm{H}_{24}$ & 204.35 & $0.26 \%$ & 9.86 & 990 \\
19 & cis-4-Thujanol & $\mathrm{C}_{10} \mathrm{H}_{18} \mathrm{O}$ & 154.25 & $0.24 \%$ & 9.25 & 975 \\
20 & Terpinolene & $\mathrm{C}_{10} \mathrm{H}_{16}$ & 136.23 & $0.22 \%$ & 19.09 & 1186 \\
21 & Germacrene D & $\mathrm{C}_{15} \mathrm{H}_{24}$ & 204.35 & $0.19 \%$ & 17.71 & 1157 \\
22 & $\alpha$-Selinene & $\mathrm{C}_{15} \mathrm{H}_{24}$ & 204.35 & $0.16 \%$ & 6.38 & 905 \\
23 & 2 -isopropyltoluene & $\mathrm{C}_{10} \mathrm{H}_{14}$ & 134.22 & $0.11 \%$ & 19.89 & 1203 \\
\hline
\end{tabular}

\subsection{Determination of Antimicrobial Activity and MIC of C. camphora EO}

The antimicrobial activity of the C. camphora EO is shown in Table 2. C. camphora EO demonstrated significant inhibitory effects against S. aureus ATCC25933, E. coli ATCC25922, P. aeruginosa, and C. violaceum ATCC31532. The inhibitory effect was enhanced with increasing concentrations of C. camphora EO and P. aeruginosa exhibited a greater inhibitory effect than S. aureus ATCC25933, E. coli ATCC25922, and C. violaceum ATCC31532 at the same concentration.

The minimum inhibitory concentration (MIC) is defined as the minimum sample concentration with no obvious bacterial growth. The MIC of C. camphora EO was assessed for all test pathogens using doubling dilution method with concentration varying from $80 \%$ o to $2.5 \%$. The MIC of C. camphora $\mathrm{EO}$ 
was $2.5 \%$ for P. aeruginosa, 5\% for S. aureus ATCC25933 and C. violaceum ATCC31532, and 10\%o for E. coli ATCC25922.

The results of antimicrobial activity and MIC indicated that P. aeruginosa and E. coli ATCC25922 showed the highest and lowest sensitivity to C. camphora EO, respectively.

Table 2. Antibacterial effect of C. camphora EO.

\begin{tabular}{|c|c|c|c|c|c|c|c|}
\hline \multirow{2}{*}{ Bacteria } & \multicolumn{6}{|c|}{ Concentration/Antimicrobial Diameters (mm) } & \multirow[b]{2}{*}{ MIC } \\
\hline & $100 \%$ & $50 \%$ & $25 \%$ & $12.5 \%$ & Methanol & $\begin{array}{l}\text { Kanamycin } \\
(250 \mu \mathrm{g} / \mathrm{mL})\end{array}$ & \\
\hline $\begin{array}{l}\text { Escherichia coli } \\
\text { ATCC25922 }\end{array}$ & $11.94 \pm 0.235^{\mathrm{ah}}$ & $11.81 \pm 0.607^{a h}$ & $10.89 \pm 0.545^{b g}$ & $8.44 \pm 0.144^{\mathrm{cg}}$ & $6.00 \pm 0.00$ & $15.72 \pm 0.15$ & $10 \%$ \\
\hline $\begin{array}{c}\text { Staphylococcus } \\
\text { aureus ATCC25933 }\end{array}$ & $14.35 \pm 0.489$ af & $13.46 \pm 0.364 \mathrm{bf}$ & $11.74 \pm 0.432 \mathrm{cf}$ & $10.22 \pm 0.020 \mathrm{df}$ & $6.00 \pm 0.00$ & $20.78 \pm 1.81$ & $5 \%$ \\
\hline $\begin{array}{c}\text { Pseudomonas } \\
\text { aeruginosa }\end{array}$ & $16.61 \pm 0.44^{\mathrm{ae}}$ & $15.19 \pm 0.60$ be & $13.59 \pm 0.41$ ce & $11.71 \pm 1.17 \mathrm{de}$ & $6.00 \pm 0.00$ & $21.02 \pm 0.41$ & $2.5 \%$ \\
\hline $\begin{array}{c}\text { Chromobacterium } \\
\text { violaceum } \\
\text { ATCC } 31532\end{array}$ & $13.93 \pm 1.09 \mathrm{ag}$ & $12.37 \pm 0.57 \mathrm{bg}$ & $11.89 \pm 0.74 \mathrm{bcf}$ & $10.52 \pm 0.17^{c f}$ & $6.00 \pm 0.00$ & $19.89 \pm 2.33$ & $5 \%$ \\
\hline
\end{tabular}

Note: Different letters (a-d) within the same row represent significant difference at the different concentration $(p<0.05)$.

Different letters $(\mathrm{e}-\mathrm{h})$ within the same line represent significant difference at the different concentration $(p<0.05)$.

\subsection{The Effect of C. camphora EO on Violacein of C. violaceum CV026}

The zone diameters of non-violacein on agar plate and the inhibition extent of violacein production in CV026 by C. camphora EO were both observed in Figure 2, which indicated that C. camphora EO had a good inhibitory effect on the QS-mediated violacein production of CV026. Thus, further experiments in the present study were performed at sub-MIC concentrations (2.5\%o, $1.25 \%$ o, $0.625 \%$, and $0.3125 \%$ o) of C. camphora EO against C. violaceum ATCC31532.

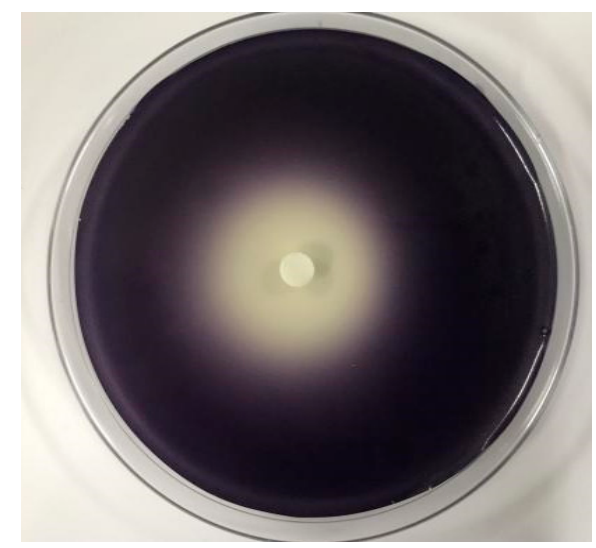

Figure 2. QSI effect of C. camphora EO on biosensor CV026.

\subsection{Growth Curve Analysis}

In the early stage of treatment (0-3 h), the C. violaceum in the treatment groups and control group was in the lag phase. At 3-6 h, the C. violaceum was in the logarithmic phase, in which the treatment groups contained different concentrations of C. camphora EO. During the later stage of treatment $(\geq 6 \mathrm{~h})$, the $C$. violaceum was in stationary phase in both the control group and the treatment groups, and there was no significant distinction among the groups (Figure 3). These results indicate that the C. camphora EO had no inhibitory effect on the growth of $C$. violaceum under the tested concentrations. We therefore assessed the specific effect of $C$. camphora EO on QS in C. violaceum. 


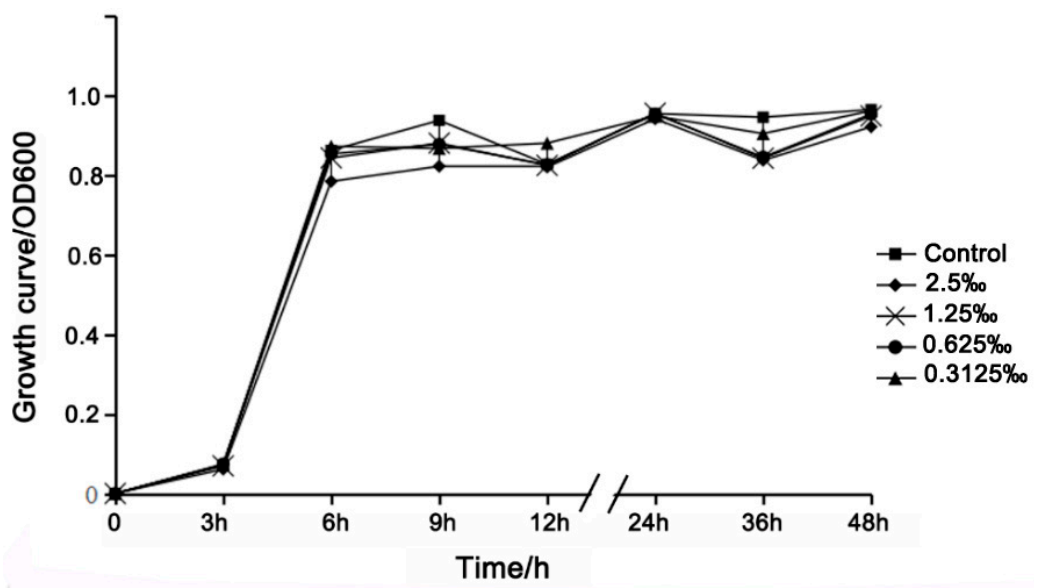

Figure 3. The effect of different concentrations of $C$. camphora EO on the growth of C. violaceum.

\subsection{Violacein Detection in C. violaceum}

The synthesis of violacein is regulated by the QS system, and violacein is usually used as a simple and intuitive indicator for screening QSIs [16]. In our assay, we observed that C. camphora EO showed a notable and concentration-dependent inhibition of violacein production, which was dependent on QS regulation (Figure 4a). The results of purification and quantitative analysis of the violacein in the culture supernatant demonstrated the inhibitory effect of $C$. camphora $\mathrm{EO}$ on violacein production, and the maximum inhibition (63\%) in C. violaceum occurred upon treatment with C. camphora EO at $2.5 \%$. (Figure 4b).

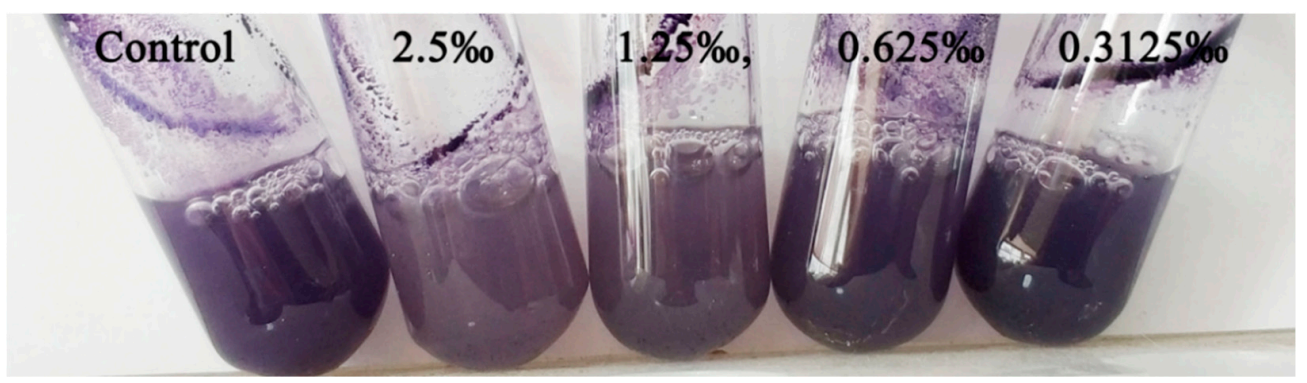

(a)

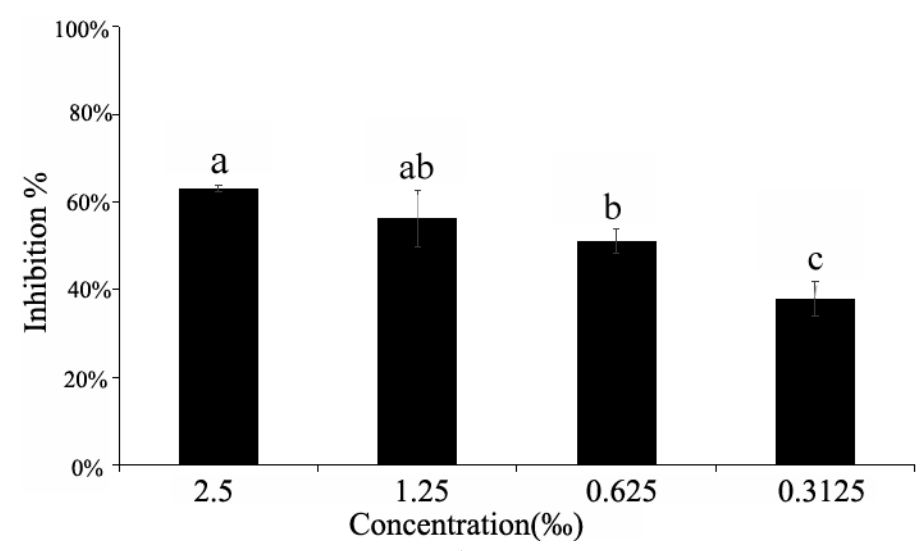

(b)

Figure 4. The effect of different concentrations of C. camphora EO on the production of violacein. (a) Effect of C. camphora EO on violacein production in C. violaceum. (b) Quantitative analysis of violacein inhibition in C. violaceum by $C$. camphora EO. Mean values of triplicate independent experiments and SD are shown. Bars indicate standard errors and different letters $(\mathbf{a}-\mathbf{c})$ above the bars represent significant differences $(p<0.05)$. 
2.6. Effect of C. camphora EO on Biofilm Development

Biofilms enhance bacterial tolerance to antibiotics, environmental pressure, and attacks by the host immune system. The formation of bacterial biofilms is regulated by the QS system [17]. The antibiofilm activity of $C$. camphora EO could be observed by biofilm staining with crystal violet (CV) (Figure 5a). The quantitative results exhibited an obvious concentration-dependent reduction in the biofilm biomass of C. violaceum. The C. camphora EO at sub-MIC (2.5\%o, 1.25\%, $0.625 \%$, and 0.3125\%o) decreased the biofilm biomass by $77.64 \%, 69.21 \%, 64.03 \%$, and $26.83 \%$, respectively (Figure $5 b$ ). In addition, we found that C. camphora EO influenced biofilm formation. Compared with the control group, the biofilms of $C$. violaceum in the EO-treated groups were distributed loosely and did not aggregate (Figure 5c). 


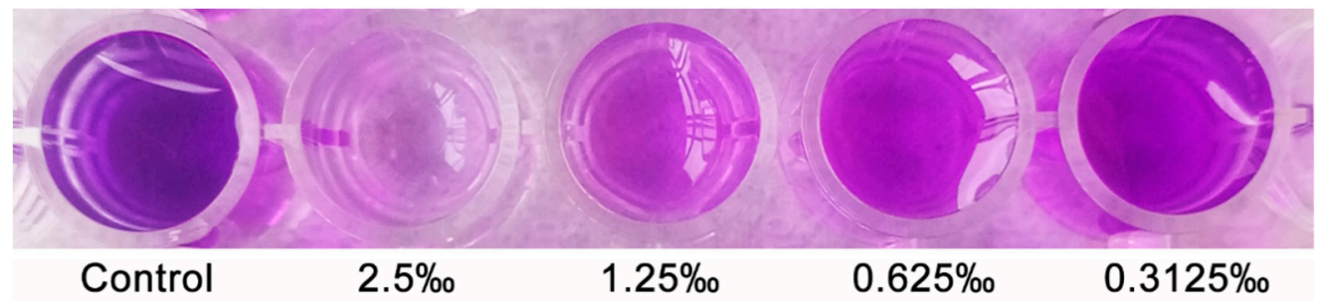

(a)

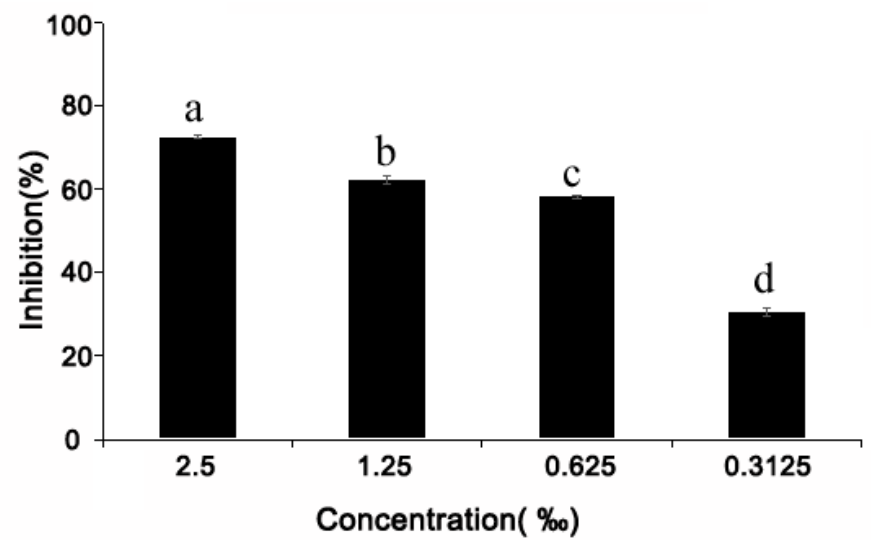

(b)

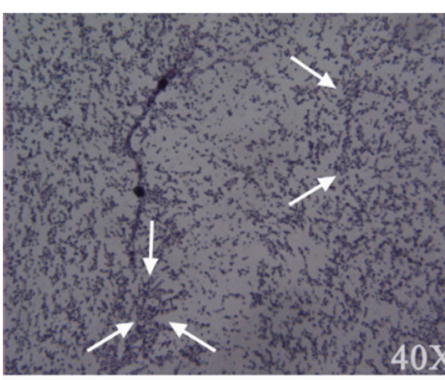

Control

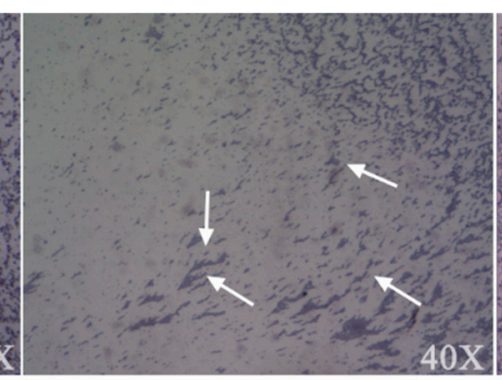

$2.5 \%$

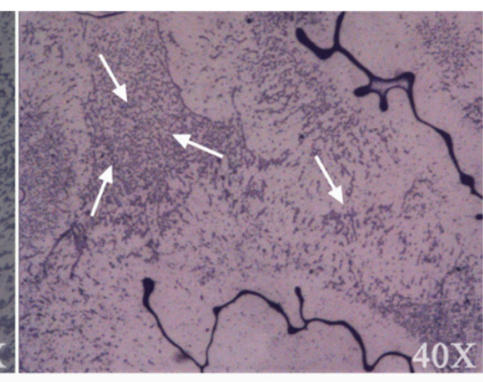

$0.625 \%$

(c)

Figure 5. The effect of different concentrations of C. camphora EO on the biofilm. (a) Dyeing effect of crystal violet on biofilm of $C$. violaceum treated with different concentrations of $C$. camphora EO. (b) Quantitative analysis of the inhibition of biofilm biomass in C. violaceum by C. camphora EO. (c) Effect of $C$. camphora $\mathrm{EO}$ on biofilm formation. Mean values of triplicate independent experiments and SD are shown. Bars indicate standard errors and different letters (a-d) above the bars represent significant differences $(p<0.05)$.

\subsection{Swarming Motility}

Swarming movement refers to the use of flagella to migrate from the inoculation point to the surrounding area. This colony-level activity depends on bioactive substances on the surface of the medium in a colony manner [18]. Swarming plays an important role in the preliminary stage of QS-regulated bacterial biofilm formation. Our results showed that C. camphora EO inhibited the swarming motility behavior of $\mathrm{C}$. violaceum, and clear inhibition was observed upon treatment with sub-MICs (2.5\%o and $0.625 \%$ ) (Figure 6). 


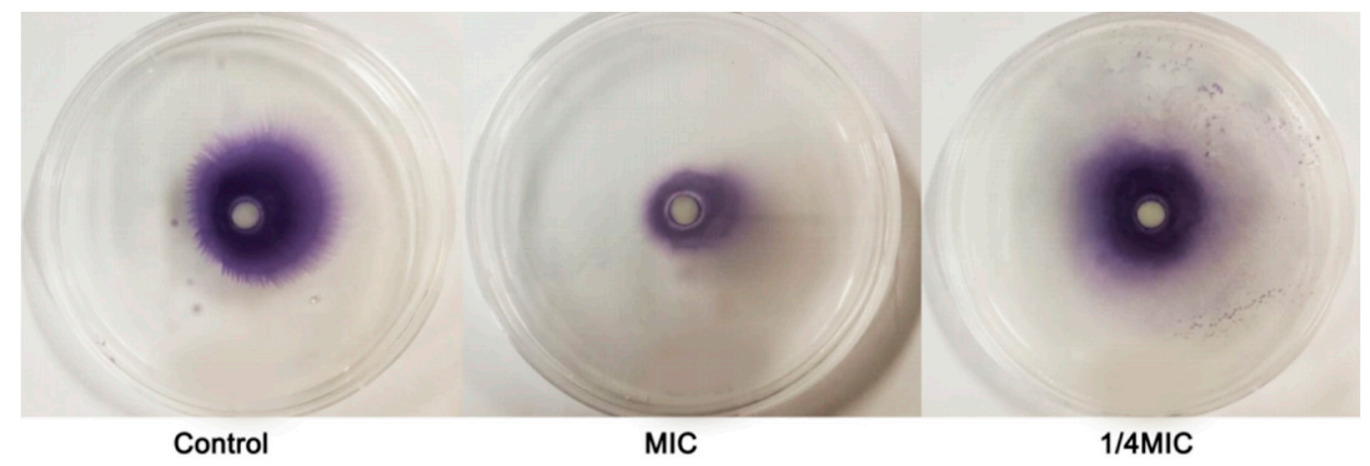

Figure 6. Inhibition of C. camphora $\mathrm{EO}$ on C. violaceum.

\subsection{Expression of the QS-Related Gene in Response to C. camphora EO}

We further assessed the effects of C. camphora $\mathrm{EO}$ on the expression of QS genes in strain C. violaceum by RT-qPCR. As expected, the expression of the cviI and cviR genes decreased with an increase of C. camphora EO concentration and displayed the concentration-dependent change, independent of a direct effect on growth rate (Figure 7).
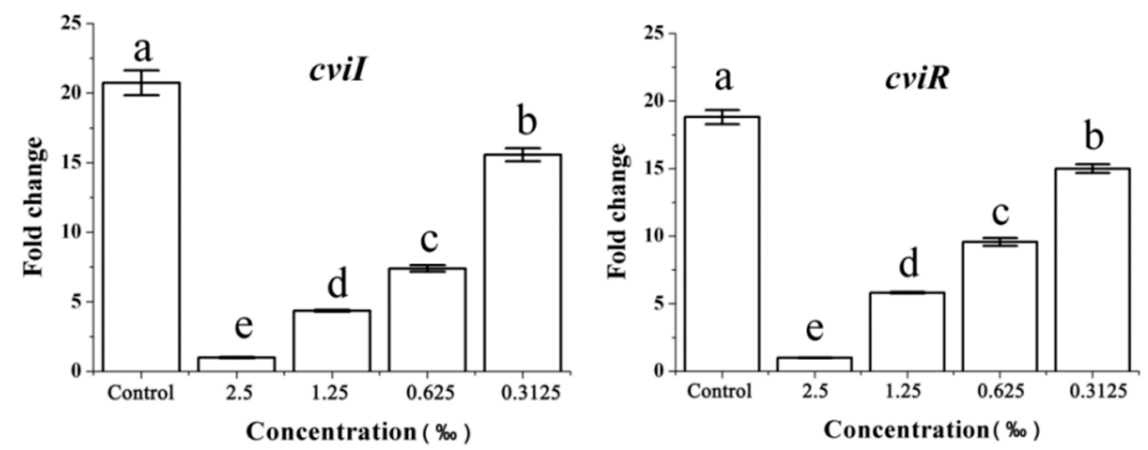

Figure 7. Effect of C. camphora EO on the expression of cviI and cviR. Quantitative RT-qPCR of the cviI and $c v i R$ genes. Expression of the housekeeping gene, $r p o D$, was used as the internal control for each sample. Bars indicate standard errors and different letters (a-e) above the bars represent significant differences $(p<0.05)$.

Violacein synthesis and biofilm formation are important virulence factors in C. violaceum. Accordingly, we also evaluated the effect of C. camphora EO on the expression levels of genes that are directly involved in violacein synthesis and biofilm formation, including vioABCDE and $h m s H N F R$. These genes are downstream of the QS cascade and are strictly controlled by the QS system [19]. The relative expression of the gene clusters vio $A, v i o B, v i o C, v i o D, v i o E, h m s H, h m s N, h m s F$, and $h m s R$ were clearly reduced by $C$. camphora EO relative to the control group (Figure 8). Furthermore, the effect of C. camphora $\mathrm{EO}$ on the relative expression of genes $l a s A-B$ and pilE3, encoding bacterial elastase and pilus, respectively, was assessed. las $A$ and $\operatorname{las} B$ genes may be involved in limiting the host response, activating inappropriate host responses [20]. PilE3, which encodes a type IV pilus protein, and these fimbriae are involved in the enhancement of QS over aggregation and biofilm formation [21]. These genes have been associated with virulence in C. violaceum, but their expression has not been reported to be directly associated with QS. Consistent with the clear effect observed on QS and QS-regulated genes, the expression of las $A-B$ and pilE3 was affected by exposure to the $C$. camphora EO (Figure 8). 

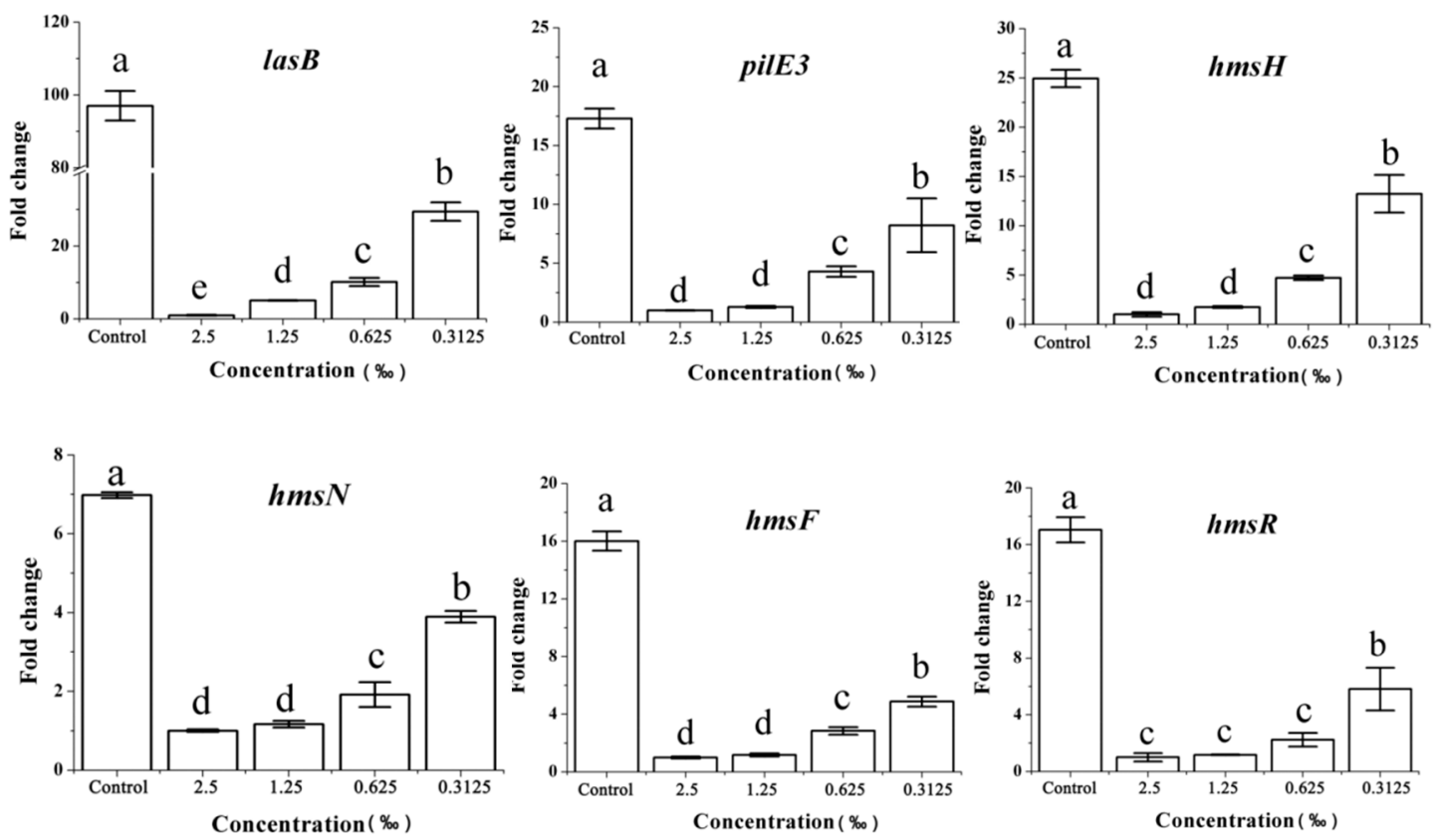

Figure 8. Effect of C. camphora EO on the expression of genes regulated by LuxI-LuxR system. Quantitative RT-qPCR of the vioA, vioB, vioC, vioD, vioE, lasA, lasB, and pilE3 genes. Expression of the housekeeping gene, $r p o D$, was used as the internal control for each sample. Bars indicate standard errors and different letters (a-e) above the bars represent significant differences $(p<0.05)$.

\section{Discussion}

Resistance to antibiotics and chemical drugs is one of the greatest public health problems. This problem is a natural consequence of the adaption of infectious pathogens to antimicrobials used in several areas, including in medicine, food animal production, crop production and disinfectants in farms, hospitals, and households [22]. To find novel antimicrobial agents with new modes of action, plants have been explored as sources for the identification of new and effective antimicrobials. Plant EOs have shown clear inhibitory effects against fungi, bacteria, and viruses. Eos are natural, environmentally protective, safe, nontoxic, and widely present, thus indicating the great value of the application and utilization of Eos [23]. Our study also showed that $C$. camphora EO had marked antibacterial activity against the pathogens, including S. aureus ATCC25933, E. coli ATCC25922, P. aeruginosa, and C. violaceum ATCC 31532. The multiple components of EOs often play a synergistic role in antibacterial activities, thus plant EOs exhibit not single-target but rather multitarget synergistic mechanisms [24].

The infection ability of bacteria can be effectively reduced by inhibiting the QS system, which will not threaten the growth of bacteria or prevent drug resistance [25]. Plant EOs exhibit great potential against pathogen contamination due to their prominent antibiofilm and anti-QS properties. Studies have shown that bacteria treated with sub-MIC concentrations of EO or their chemical individual constituents (ICs) were highly insensitive to bactericides and physical treatments, indicating that EOs or their ICs could reduce the incidence of bacterial drug resistance [26,27]. While planktonic bacteria are already resistant to many antimicrobials, in biofilms this resistance can increase several times. Biofilms may be formed on a variety of surfaces including living tissues, indwelling medical devices, and contact lenses [28]. Biofilm formation by pathogens is one of the most notable aspects of their pathogenicity and resistance, and QS plays a vital role in biofilm formation, thus interference with the QS system might be a preferable and convenient method to block its pathogenicity [25]. The inhibition of pathogen biofilms by C. camphora $\mathrm{EO}$ can effectively reduce the incidence of bacterial drug resistance, which makes this EO a suitable agent to combat pathogens. 
QSIs interfered with the QS system primarily through the following three pathways: (1) the signaling molecule synthesis protein LuxI is affected such that the signal molecules, known as autoinducers (AIs), cannot be produced normally; (2) by degradation of the signaling molecules (AIs) to interfere with the expression of QS-related genes, even when the cell reaches the threshold population density; and (3) by prevention of the binding of the signaling molecule (AHL) to receptor protein LuxR, resulting in the inactivation of the transcriptional functions [29]. Plant phenolic aromatic compounds, including carvacrol and eugenol, directly interact with the signal molecule synthase and receptor proteins of Pectobacterium aroidearum PC1 and P. carotovorum subsp. brasiliense Pcb1692, thereby inhibiting the expression of QS-related genes, the biofilm formation, and synthesis of plant cell wall degradation enzymes (PCWDE) [30]. Our results showed that the C. camphora EO (sub-MIC) disturbed the swarming movement of $C$. violaceum, reduced the production of violacein and biofilm biomass, and inhibited biofilm formation. Inhibition of the QS major components (CviI/CviR) and virulence genes (vioA, vioB, vioC, vioD, vioE, las A, lasB pilE3, and hmsHNFR) exposed to C. camphora EO was further reflected in lower virulence activities (violacein production, biofilm formation, and swarming movement). Our studies showed that $C$. camphora EO can reduce the bacterial pathogenicity by quenching bacterial QS instead of killing bacteria, providing a new pathway for the biological control of bacterial contamination.

Studies have shown that linalool and eucalyptol, as the main components in C. camphora EO, are capable of inhibiting bacterial biofilm formation [31,32]. We inferred that linalool $(51.57 \%)$ and eucalyptol $(22.07 \%)$ might be the important factors that interfered with the QS activity of C. violaceum. Linalool and eucalyptol may interfere synergistically with the AHL synthase and/or receptor proteins LuxR of C. violacem and regulate the expression of QS genes, thus affecting related physiological activities. The specific regulatory mechanisms still require further study. In the future, we plan to isolate bacterial QSIs from the C. camphora EO using the QS activity tracing method to clarify the regulatory mechanism and provide new methods for the biological control of pathogen contamination.

\section{Materials and Methods}

\subsection{Materials}

Cinnamomum camphora leaf was harvested on the campus of Fujian Agriculture and Forestry University (Fujian, China); a voucher specimen of the plant (Cinnamomum camphora (L.) Presl. officinal bar code No 00189531) was confirmed and deposited in the Institute of Botany, Chinese Academy of Sciences. The C. camphora leaf (Cinnamomum camphora (L.) Presl) in this study was identified by Professor Fangying Li in the College of Art and Landscape Architecture of Fujian Agriculture and Forestry University (Fujian, China).

Bacterial strains, medium, growth conditions: Chromobacterium. violaceum ATCC31532, Chromobactrium violaceum CV026, Staphylococcus aureus ATCC25933, Escherichia coli ATCC25922, and Pseudomonas aeruginosa were stored in the College of Horticulture in Fujian Agriculture and Forestry University (Fujian, China), and inoculated in LB broth and grown under the conditions of $30^{\circ} \mathrm{C}$, $150 \mathrm{rpm}$ for $12 \mathrm{~h}$.

$\mathrm{N}$-hexanoyl-L-homoserine lactone (C6-HSL) was purchased from Sigma-Aldrich (Germany). $\mathrm{n}$-alkanes (C8 C20) standard solution was purchased in Fluka.

\subsection{Equipment}

The gas chromatography-mass spectrometry technology (GC-MS) (GC, Clarus ${ }^{\circledR} 680$; MS, SQ8T; Perkin Elmer (USA), Shanghai branch (China)), ultraviolet spectrophotometer (U-290, Hitachi Company, Tokyo, Japan), Biobiology incubator (BPMJ-150F, Yiheng Company, Shanghai, China), ELISA (iMark, Bio-Rad Company, Hercules, CA, USA). 
Extraction of C. camphora EO by Steaming

$50 \mathrm{~g}$ of C. camphora leaf was placed in a round-bottom flask supplemented with distilled water at a 1:10 ratio. The EO was distilled in the essential oil extractor. The $C$. camphora EO was collected and the yield was calculated, and the calculation formula was shown in Equation (1). The experiment was repeated three times.

$$
\text { Yield of essential oil }(\%)=(\text { weight of essential oil/weight of leaf }) \times 100 \%
$$

\subsection{Determination of Components of C. camphora EO by GC-MS}

The C. camphora EO was subjected to a GC-MS analysis using a GC (Clarus ${ }^{\circledR} 680$ ) equipped with a mass selective detector (SQ8T) in the electronic ionization (EI) mode and Turbomass Ver 6.1.0 software. The method was performed by using the following procedure with slight modification $[33,34]$. Sample injection was performed in split mode (20:1) into a DB-5MS capillary column, $30 \mathrm{~m} \times 25 \mathrm{~mm} \times 0.25 \mu \mathrm{m}$ film thickness coated with 5\% Ph Me Siloxane. Helium was used as the carrier gas at $1 \mathrm{~mL} \mathrm{~min}^{-1}$. The GC injector temperature was set at $200{ }^{\circ} \mathrm{C}$. The oven temperature program was optimized to hold at $60{ }^{\circ} \mathrm{C}$ for $5 \mathrm{~min}$, then heat to $150{ }^{\circ} \mathrm{C}$ at a rate of $3{ }^{\circ} \mathrm{C} / \mathrm{min}$ (maintain for $5 \mathrm{~min}$ ), and finally increase by $50{ }^{\circ} \mathrm{C} / \mathrm{min}$ up to $250^{\circ} \mathrm{C}$ (maintained for $2 \mathrm{~min}$ ). The transfer line temperature was adjusted to $200{ }^{\circ} \mathrm{C}$. Mass spectrometry conditions were as follows: electron ionization source set to $70 \mathrm{eV}$, MS transmission line to $250{ }^{\circ} \mathrm{C}$, MS source to $230{ }^{\circ} \mathrm{C}$. The mass spectrometer was run in full-scan mode $(m / z 45-550)$. The essential oil production was analyzed by peak area.

The essential compounds were identified on the basis of a comparison of their retention index (RI) relative to n-alkanes (C8 C20), standard substance, as well as published data and EI mass spectra from the literature. Compounds were further compared and their MS data authenticated to the National Institute of Standards and Technology mass spectral library (NIST). The relative mass fraction of the EO was calculated using the peak area normalization method. The formula for retention index (RI) $[35,36]$ is as follows in Equation (2):

$$
\mathrm{RI}=100 Z+100[\mathrm{RT}(\mathrm{x})-\mathrm{RT}(\mathrm{z})] /[\mathrm{RT}(\mathrm{Z}+1)-\mathrm{RT}(\mathrm{z})]
$$

where $\mathrm{Z}=$ the number of $\mathrm{C}$ in the smaller alkane; $\mathrm{RT}(\mathrm{x})=$ the retention time of the unknown compound; $\mathrm{RT}(\mathrm{z})=$ the retention time of the smaller alkane; $\mathrm{RT}(\mathrm{z}+1)=$ the retention time of the larger alkane.

\subsection{The Determination of Antimicrobial Activity and MIC of C. camphora EO}

The test strains, S.aureus ATCC25933, E.coli ATCC25922, P. aeruginosa, and C. violaceum ATCC31532 were cultured in LB broth at $150 \mathrm{rpm}, 30{ }^{\circ} \mathrm{C}$ for $12 \mathrm{~h}$. The C. camphora EO was serially diluted to $50 \%$, $25 \%$, and $12.5 \%$ with methanol. The plate perforation method was performed by using the following procedure with some modification [37]. Briefly, $1 \%$ overnight cultured test bacterium was added to the heated LB medium (containing $2 \%$ agar) at a temperature of $50{ }^{\circ} \mathrm{C}$. After blending, the mixing was poured into the petri dishes quickly. Then, the solidified LB medium was punched with $6 \mathrm{~mm}$ holes every $120^{\circ}$ in the petri dishes. A $25 \mu \mathrm{L}$ volume of C. camphora $\mathrm{EO}$ at different concentrations $(100 \%, 50 \%, 25 \%$, and $12.5 \%)$ was added to the holes. The culture plates were incubated at $30{ }^{\circ} \mathrm{C}$. The antimicrobial activity was measured by the antimicrobial diameters. Methanol and kanamycin (250 ug/mL) were used as negative control and positive control, respectively.

Doubling dilution method was applicable to test the minimum inhibitory concentrations (MIC) of C. camphora EO. The method was performed by using the following procedure with some modification [38]. Briefly, 1\% of C. violaceum ATCC31532, S. aureus ATCC25933, E. coli ATCC25922, P. aeruginosa were added to LB medium $(150 \mu \mathrm{L})$ supplemented with twofold serially diluted C. camphora $\mathrm{EO}(150 \mu \mathrm{L})$ to attain final concentration ranging from $2.5 \%$ o to $80 \%$ of an equal final volume in $1.5 \mathrm{~mL}$ microcentrifuge tube, which was incubated for $24 \mathrm{~h}\left(30^{\circ} \mathrm{C}, 150 \mathrm{rpm}\right)$. The OD600 was measured. 


\subsection{Quorum-Sensing Inhibition (QSI) Assays of C. camphora EO}

Quorum-sensing inhibition (QSI) assay was performed according to the procedure described by Zhang et al. [39] with a few modifications. An overnight culture of CV026 (1\%) was spread on LB plates $(20 \mathrm{~mL})$, and then C6-HSL solution $(2 \mu \mathrm{L}, 50 \mathrm{mg} / \mathrm{mL})$ was added to the plates. The filter paper ( $6 \mathrm{~mm}$ in diameter) was then placed into the center of the plate. Next, the C. camphora EO $(15 \mu \mathrm{L})$ was added to the filter paper, and the plates were incubated for $24 \mathrm{~h}$ at $30^{\circ} \mathrm{C}$. QSI was assessed from the formation of a ring of inhibition extent of violacein production around the filter paper.

\subsection{Growth Curve Analysis}

The $1 \%$ C. violaceum was incubated in a $250 \mathrm{~mL}$ Erlenmeyer flask containing $20 \mathrm{~mL}$ of LB broth supplemented with different concentrations of $C$. camphora EO (sub-MIC, $1.2 \mathrm{~mL}$ ). The mixes were cultured at $30^{\circ} \mathrm{C}$, under $150 \mathrm{rpm}$ in a rotatory shaker. Bacterial growth was determined by UV-visible spectrophotometry at OD600 during a 3-48 h period.

\subsection{Violacein Detection in C. violaceum}

Violacein synthesis of $C$. violaceum strain ATCC31532 was regulated by the quorum sensing [40]. An overnight culture of $1 \%$ C. violaceum was added into a glass tube containing $5 \mathrm{~mL}$ LB broth supplemented with various concentrations (sub-MIC, $300 \mu \mathrm{L}$ ) of C. camphora EO. The mixture was incubated at $30^{\circ} \mathrm{C}$ for $24 \mathrm{~h}$. The specific methods were followed as described [41]. Briefly, $1 \mathrm{~mL}$ of the above solution was collected and centrifuged at $4{ }^{\circ} \mathrm{C}$ for $20 \mathrm{~min}$. The supernatant was removed and $1 \mathrm{~mL}$ dimethyl sulfoxide (DMSO) was added to the centrifuge tube. After vortexing, the violacein was dissolved in DMSO at room temperature and centrifuged for $3 \mathrm{~min}$ to remove the bacterium. Violacein production was measured by UV-visible spectrophotometry at OD595, and the calculation formula was shown in Equation (3). Each assay was performed in triplicate.

Violacein inhibition rate $(\%)=\left(\right.$ OD595 $($ Contol group $)-$ OD595 $\left._{(\text {Treatment group })}\right) / O D 595_{(\text {Contol group })} \times 100 \%$

\subsection{Effect of C. camphora EO on Biofilm Development}

The effect of $C$. camphora EO on biofilms was determined by quantifying the biofilm biomass using a microtiter dish with crystal violet (CV) and microtiter dish assay [42]. An overnight culture of $1 \%$ C. violaceum was added into a 96-well dish containing $200 \mu \mathrm{L}$ of LB broth supplemented with various concentrations of C. camphora EO (sub-MIC, $6 \% v / v$ ). The mixture was incubated at $30^{\circ} \mathrm{C}$ for $24 \mathrm{~h}$. After incubation, the unattached cells and media components were removed with distilled water. Then, $250 \mu \mathrm{L}$ of a $0.1 \%$ solution of $\mathrm{CV}$ was added to each well of the microtiter plate and incubated at room temperature for 10-15 min. Finally, the 30\% acetic acid was added for further determination. The absorbance at $600 \mathrm{~nm}$ was read in a microplate reader and recorded as the absorbance of CV dye bound to the bacterial biofilm. Each assay was performed in eight replicates.

To identify the ability of $C$. camphora EO to disrupt the biofilm, a biofilm disrupting assay was performed by following the revised method [43]. Briefly, the test pathogens treated with different concentrations of $C$. camphora EO (sub-MIC) were incubated in a 24-well plate with cover glasses $1 \times 1 \mathrm{~cm}$ for $24 \mathrm{~h}$ and then were observed under a light microscope.

\subsection{Swarming Motility}

We examined the effect of $C$. camphora $\mathrm{EO}$ on the swarming motility in C. violaceum, following a previously described method [13]. Simply, $5 \mu \mathrm{L}$ overnight cultured bacterium was incubated in $6 \mathrm{~mm}$ filter paper at the center of the swarming motility medium containing $1 \%$ tryptone, $0.5 \% \mathrm{NaCl}, 0.5 \%$ agar, and $0.5 \%$ of D-glucose. Swarming motility was measured by the migration distance. 


\subsection{Gene Expression Analysis}

$1 \%$ C. violaceum (OD600, 0.9) was incubated with $20 \mathrm{~mL}$ LB containing a range of concentrations sub-MIC of C. camphora EO (1.2 mL). Cultures were grown for $24 \mathrm{~h}$, the cells were harvested by centrifugation $(12,000 \times g, 2 \mathrm{~min})$, and supernatant was discarded. Total RNA was extracted using an RNAprep Pure Cell/Bacteria Kit (Code No. DP430, TIANGEN, China), according to the manufacturer's guidelines. The RNA was used for reverse transcription, using Transcript One-Step gDNA Removal and cDNA Synthesis SuperMix (Transgen, China). The oligonucleotide primers were designed and are listed in Table 3. Quantitative RT-qPCR was performed using Real-Time PCR Master Mix (SYBR Green) (Transgen, China) under the following conditions: two steps of $30 \mathrm{~s}$ at $94{ }^{\circ} \mathrm{C}$ and 40 cycles of $94^{\circ} \mathrm{C}$ for $5 \mathrm{~s}, 60^{\circ} \mathrm{C}$ for $30 \mathrm{~s}$. The calculated cycle threshold of each gene was normalized to the CT for $r p o D$ amplified from the corresponding sample. The RT-qPCR was performed in Light cycler96 (Roche company, France). Fold changes in gene expression were calculated according to the $2^{-\Delta \Delta C T}$ method.

Table 3. PCR Primers for Fluorescence Real-Time Quantitative PCR.

\begin{tabular}{|c|c|c|}
\hline Gene & Forward $\left(5^{\prime}-3^{\prime}\right)$ & Reverse $\left(5^{\prime}-3^{\prime}\right)$ \\
\hline cviI & GAAACCGTCCTCGCATAAGG & ACAAGGTGGACTGGTACTGG \\
\hline$c v i R$ & CCCAGCAATATGCCGCTATC & CATTGAGCTTGCGGATCACA \\
\hline vioA & AAGAGCATGGCAAGGAATC & CTGGTTGGCGTCGTTATC \\
\hline vioB & CTGGGCGTAATTGGGAATGG & CAAATACCTGGCCCATGTCG \\
\hline vioC & GAACAAGTACGCCAACCT & GGAAGAAAGTCTGCTGGAA \\
\hline vioD & GCCGCAACAAGTACATCT & GAAGGTGCTCATCGTGTC \\
\hline vioE & ATAGGCCACCTTCTGCTTCC & GGCTACTGCTGGTTCGACTA \\
\hline$h m s H$ & CGCCGTATGTCTTCAGTT & CGCAGCCTATCGTAGATG \\
\hline$h m s F$ & GGCTGCTGATTCTCTGTTA & GTATAGACGCTGCGGTAG \\
\hline$h m s N$ & AAACCACACGCACCAGAAC & TGCATGAGCATGAAGACGAC \\
\hline $\operatorname{las} A$ & AGCCAGCCTTACGATTCCAT & GAGGAATAGCCGTTGTCGTG \\
\hline las $B$ & AGAACGCCTTGTTGTACACG & GCAAGAACGACTTCCTGGTC \\
\hline pilE3 & TACGCTGGTCGAGTTGATGA & GCGAATAGCACTGCTCCATC \\
\hline $\begin{array}{l}\text { rpoD } \\
\text { (actin) }\end{array}$ & TCGGACATCAGCAAGGTT & GTGAAGGACAGCCAACAG \\
\hline
\end{tabular}

\subsection{Statistics Analysis}

All experiments were performed at least in triplicates and all data were analyzed by SPSS 19.0 software and presented as mean values. Differences with $p<0.05$ were considered statistically significant.

\section{Conclusions}

Twenty-three components with a relative mass fraction of $\geq 0.11 \%$ were identified in C. camphora EO, and the principal component was linalool (51.57\%), which indicated that the species belongs to the linalool type.

The C. camphora EO had a significant inhibitory effect against S. aureus ATCC25933, E. coli ATCC25922, P. aeruginosa, and C. violaceum ATCC31532. In addition, the MICs of C. camphora EO were 2.5\% for P. aeruginosa, 5\%o for S. aureus ATCC25933 and C. violaceum ATCC31532, and 10\%o for E. coli ATCC25922. Thus P. aeruginosa and E. coli ATCC25922 showed the highest and least sensitivity to C. camphora $\mathrm{EO}$, respectively.

The C. camphora EO also interfered with the QS phenotype behaviors without inhibiting its growth, primarily as follows: the violacein and biofilm were reduced with the maximum inhibition rates of $63 \%$ and $77.64 \%$, respectively. Biofilm formation and the swarming movement of C. violaceum were inhibited upon treatment with C. camphora EO. Furthermore, the expression of QS-related genes decreased significantly in the presence of C. camphora EO at sub-MICs. 
Quorum-sensing quenching could be an alternative strategy to combat bacterial infections as it lowers the development of multidrug resistance. The anti-QS activity of $C$. camphora EO lays a foundation for developing camphor EO into a new biological pesticide targeting the bacterial QS system. However, the further study of the interaction mechanism between $\mathrm{EO}$ and bacteria should be analyzed in detail.

Author Contributions: This experimental design was conceived by W.W., S.W., C.Y., and Y.L. The experiments were performed by W.W., D.L., H.Y., and X.H. Data analysis was performed by W.W., Y.S., Z.Q., Y.W., Q.L. and L.Z. W.W. and D.L. drafted the manuscript. All authors read and approved the final version of the manuscript.

Funding: This study was financially supported by the National Natural Science Foundation of China (Grant Nos. 31501694 and 31902067), the Foundation of Fujian Science and Technology Committee (Grant No. 2018N0003), the Foundation of Fuzhou Science and Technology Committee (Grant No. 2017NF30048), and the Foundation of Qingyuan Science and Technology Committee (Grant No. 2018A013).

Acknowledgments: Li's work on this project was provided a formal identification of the plant material, Cinnamomum camphora.

Conflicts of Interest: The authors declare no conflict of interest.

\section{References}

1. Marinelli, L.; Stefano, A.D.; Cacciatore, I. Carvacrol and its derivatives as antibacterial agents. Phytochem. Rev. 2018, 17, 903-921. [CrossRef]

2. Fuqua, W.C.; Winans, S.C.; Greenberg, E.P. Quorum sensing in bacteria: The LuxR-LuxI family of cell density-responsive transcriptional regulators. J. Bacteriol. 1994, 176, 269-275. [CrossRef] [PubMed]

3. Rahman, M.R.T.; Lou, Z.; Yu, F.; Wang, P.; Wang, H. Anti-quorum sensing and anti-biofilm activity of Amomum tsaoko on foodborne pathogens. Saudi J. Biol. Sci. 2017, 24, 324-330. [CrossRef] [PubMed]

4. Adonizio, A.; Kong, K.F.; Mathee, K. Inhibition of quorum sensing-controlled virulence factor production in Pseudomonas aeruginosa by South Florida plant extracts. Antimicrob. Agents Chemother. 2008, 52, 198-203. [CrossRef] [PubMed]

5. Ta, C.A.; Freundorfer, M.; Mah, T.F.; Otárola-Rojas, M.; Garcia, M.; Sanchez-Vindas, P.; Poveda, L.; Maschek, J.A.; Baker, B.J.; Adonizio, A.L.; et al. Inhibition of bacterial quorum sensing and biofilm formation by extracts of neotropical rainforest plants. Planta Med. 2014, 80, 343-350. [CrossRef]

6. Dastidar, S.G.; Kristiansen, J.E.; Molnar, J.; Amaral, L. Role of Phenothiazines and Structurally Similar Compounds of Plant Origin in the Fight against Infections by Drug Resistant Bacteria. Antibiotics 2013, 2, 58-72. [CrossRef]

7. Noumi, E.; Merghni, A.; M Alreshidi, M.; Haddad, O.; Akmadar, G.; De Martino, L.; Mastouri, M.; Ceylan, O.; Snoussi, M.; Al-Sieni, A. Chromobacterium violaceum and Pseudomonas aeruginosa PAO1: Models for Evaluating Anti-Quorum Sensing Activity of Melaleuca alternifolia Essential Oil and Its Main Component Terpinen-4-ol. Molecules 2018, 23, 2672. [CrossRef]

8. Durán, M.; Faljoni-Alario, A.; Durán, N. Chromobacterium violaceum and its important metabolites-review. Folia Microbiol. 2010, 55, 535-547. [CrossRef]

9. Trinetta, V.; Morgan, M.T.; Coupland, J.N.; Yucel, U. Essential Oils Against Pathogen and Spoilage Microorganisms of Fruit Juices: Use of Versatile Antimicrobial Delivery Systems. J. Food Sci. 2017, 82, 471-476. [CrossRef]

10. Husain, F.M.; Ahmad, I.; Khan, M.S.; Ahmad, E.; Tahseen, Q.; Khan, M.S.; Alshabib, N.A. Sub-MICs of Mentha piperita essential oil and menthol inhibits AHL mediated quorum sensing and biofilm of Gram-negative bacteria. Front. Microbiol. 2015, 6, 1-12. [CrossRef]

11. Vattem, D.A.; Mihalik, K.; Crixell, S.H.; Mclean, R.J.C. Dietary phytochemicals as quorum sensing inhibitors. Fitoterapia 2007, 78, 302-310. [CrossRef] [PubMed]

12. Yap, P.S.; Krishnan, T.; Chan, K.G.; Lim, S.H. Antibacterial Mode of Action of Cinnamomum verum Bark Essential Oil, Alone and in Combination with Piperacillin, Against a Multi-Drug-Resistant Escherichia coli Strain. J. Microbiol. Biotechnol. 2015, 25, 1299-1306. [CrossRef] [PubMed]

13. Packiavathy, I.A.S.V.; Priya, S.; Pandian, S.K.; Ravi, A.V. Inhibition of biofilm development of uropathogens by curcumin -An anti-quorum sensing agent from Curcuma longa. Food Chem. 2014, 148, 453-460. [CrossRef] [PubMed] 
14. Chang, C.Y.; Krishnan, T.; Wang, H.; Chen, Y.; Yin, W.F.; Chong, Y.M.; Tan, L.Y.; Chong, T.M.; Chan, K.G. Non-antibiotic quorum sensing inhibitors acting against $\mathrm{N}$-acyl homoserine lactone synthase as druggable target. Sci. Rep. 2014, 4, 7245. [CrossRef] [PubMed]

15. Ying, Z.; Yan, W. Conservation and applications of camphor tree (Cinnamomum camphora) in China: Ethnobotany and genetic resources. Genet. Resour. Crop Evol. 2016, 63, 1049-1061.

16. Duarte, A.; Luís, Â.; Oleastro, M.; Domingues, F.C. Antioxidant properties of coriander essential oil and linalool and their potential to control Campylobacter spp. Food Control 2016, 61, 115-122. [CrossRef]

17. Kim, M.K.; Zhao, A.; Wang, A.; Brown, Z.Z.; Muir, T.W.; Stone, H.A.; Bassler, B.L. Surface-attached molecules control Staphylococcus aureus quorum sensing and biofilm development. Nat. Microbiol. 2017, 2, 17080. [CrossRef]

18. Verstraeten, N.; Braeken, K.; Debkumari, B.; Fauvart, M.; Fransaer, J.; Vermant, J.; Michiels, J. Living on a surface: Swarming and biofilm formation. Trends Microbiol. 2008, 16, 496-506. [CrossRef]

19. Ghosh, R.; Tiwary, B.K.; Kumar, A.; Chakraborty, R. Guava Leaf Extract Inhibits Quorum-Sensing and Chromobacterium violaceum Induced Lysis of Human Hepatoma Cells: Whole Transcriptome Analysis Reveals Differential Gene Expression. PLoS ONE 2014, 9, e107703. [CrossRef]

20. Zins, M.M.; Zimprich, C.A.; Petermann, S.R.; Rust, L. Expression and partial characterization of an elastase from Chromobacterium violaceum. Vet. Microbiol. 2001, 80, 63-74. [CrossRef]

21. de Oca-Mejía, M.M.; Castillo-Juarez, I.; Martinez-Vazquez, M.; Soto-Hernandez, M.; Garcia-Contreras, R. Influence of quorum sensing in multiple phenotypes of the bacterial pathogen Chromobacterium violaceum. Pathog. Dis. 2015, 73, 1-4. [CrossRef] [PubMed]

22. Monte, J.; Abreu, A.; Borges, A.; Simões, L.; Simões, M. Antimicrobial activity of selected phytochemicals against Escherichia coli and Staphylococcus aureus and their biofilms. Pathogens 2014, 3, 473-498. [CrossRef] [PubMed]

23. Tu, X.-F.; Hu, F.; Thakur, K.; Li, X.-L.; Zhang, Y.-S.; Wei, Z.-J. Comparison of antibacterial effects and fumigant toxicity of essential oils extracted from different plants. Ind. Crop. Prod. 2018, 124, 192-200. [CrossRef]

24. Klein, G.; Rüben, C.; Upmann, M. Antimicrobial activity of essential oil components against potential food spoilage microorganisms. Curr. Microbiol. 2013, 67, 200-208. [CrossRef] [PubMed]

25. Zhou, J.-W.; Luo, H.-Z.; Jiang, H.; Jian, T.-K.; Chen, Z.-Q.; Jia, A.-Q. Hordenine: A novel quorum sensing inhibitor and antibiofilm agent against Pseudomonas aeruginosa. J. Agric. Food Chem. 2018, 66, 1620-1628. [CrossRef]

26. da Silva Luz, I.; Gomes-Neto, N.J.; Magnani, M.; de Souza, E.L. Assessment of tolerance induction by Origanum vulgare L. essential oil or carvacrol in Pseudomonas aeruginosa cultivated in a meat-based broth and in a meat model. Food Sci. Technol. Int. 2015, 21, 571-580. [CrossRef]

27. Gomes-Neto, N.J.; Luz, I.S.; Franco, O.L.; Magnani, M.; Souza, E.L. Tolerance evaluation in Salmonella enterica serovar T yphimurium challenged with sublethal amounts of Rosmarinus officinalis L. essential oil or 1, 8-cineole in meat model. Int. J. Food Sci. Technol. 2014, 49, 1912-1917. [CrossRef]

28. Zhao, X.; Zhao, F.; Wang, J.; Zhong, N. Biofilm formation and control strategies of foodborne pathogens: Food safety perspectives. RSC Adv. 2017, 7, 36670-36683. [CrossRef]

29. Brackman, G.; Nelis, H.J.; Coenye, T.; Tegos, A.; Mylonakis, E. Inhibition of Quorum Sensing as a Novel Antimicrobial Strategy. In Antimicrobial Drug Discovery: Emerging Strategies; Tegos, G., Mylonakis, E., Eds.; CABI: Wallingford, UK, 2012; pp. 115-134.

30. Joshi, J.R.; Khazanov, N.; Senderowitz, H.; Burdman, S.; Lipsky, A.; Yedidia, I. Plant phenolic volatiles inhibit quorum sensing in pectobacteria and reduce their virulence by potential binding to ExpI and ExpR proteins. Sci. Rep. 2016, 6, 38126. [CrossRef]

31. Manoharan, R.K.; Lee, J.H.; Kim, Y.G.; Kim, S.I.; Lee, J. Inhibitory effects of the essential oils $\alpha$-longipinene and linalool on biofilm formation and hyphal growth of Candida albicans. Biofouling 2017, 33, 143-155. [CrossRef]

32. Alves, S.; Duarte, A.; Sousa, S.; Domingues, F.C. Study of the major essential oil compounds of Coriandrum sativum against Acinetobacter baumannii and the effect of linalool on adhesion, biofilms and quorum sensing. Biofouling 2016, 32, 155-165. [CrossRef] [PubMed]

33. Chen, J.Y.; Ye, Z.M.; Huang, T.Y.; Chen, X.D.; Li, Y.Y.; Wu, S.H. Identification of volatiles in leaves of Alpinia zerumbet 'Variegata' using headspace solid-phase microextraction-gas chromatography-mass spectrometry. Nat. Prod. Commun. 2014, 9, 999. [CrossRef] [PubMed] 
34. Li, Y.; Ye, Z.; Wang, W.; Yang, C.; Liu, J.; Zhou, L.; Shen, Y.; Wang, Z.; Chen, J.; Wu, S. Composition Analysis of Essential Oil from Melaleuca bracteata Leaves Using Ultrasound-assisted Extraction and its Antioxidative and Antimicrobial Activities. BioResources 2018, 13, 8488-8504. [CrossRef]

35. Lucero, M.; Estell, R.; Tellez, M.; Fredrickson, E. A retention index calculator simplifies identification of plant volatile organic compounds. Phytochem. Anal. 2010, 20, 378-384. [CrossRef] [PubMed]

36. Vandendool, H.; Kratz, P.D. A Generalization of the Retention Index System Including Linear Temperature Programmed Gas_Liquid Partition Chromatography. J. Chromatogr. A 1963, 11, 463-471. [CrossRef]

37. Andotra, S.; Kalgotra, N.; Pandey, S.K. Syntheses, Characterization, Thermal, and Antimicrobial Studies of Lanthanum(III) Tolyl/Benzyldithiocarbonates. Bioinorg. Chem. Appl. 2014, 2014, 780631. [CrossRef] [PubMed]

38. Wu, D.; Huang, W.; Duan, Q.; Li, F.; Cheng, H. Sodium houttuyfonate affects production of N-acyl homoserine lactone and quorum sensing-regulated genes expression in Pseudomonas aeruginosa. Front. Microbiol. 2014, 5, 635. [CrossRef]

39. Zhang, Y.; Kong, J.; Huang, F.; Xie, Y.; Guo, Y.; Cheng, Y.; Qian, H.; Yao, W. Hexanal as a QS inhibitor of extracellular enzyme activity of Erwinia carotovora and Pseudomonas fluorescens and its application in vegetables. Food Chem. 2018, 255, 1. [CrossRef]

40. Chernin, L.S.; Winson, M.K.; Thompson, J.M.; Haran, S.; Bycroft, B.W.; Chet, I.; Williams, P.; Stewart, G.S. Chitinolytic activity in Chromobacterium violaceum: Substrate analysis and regulation by quorum sensing. J. Bacteriol. 1998, 180, 4435-4441.

41. Khan, M.S.A.; Zahin, M.; Hasan, S.; Husain, F.M.; Ahmad, I. Inhibition of quorum sensing regulated bacterial functions by plant essential oils with special reference to clove oil. Lett. Appl. Microbiol. 2010, 49, 354-360. [CrossRef]

42. O'Toole, G.A. Microtiter dish biofilm formation assay. J. Vis. Exp. Jove 2011, 47, e2437. [CrossRef] [PubMed]

43. Packiavathy, I.A.S.V.; Agilandeswari, P.; Musthafa, K.S.; Pandian, S.K.; Ravi, A.V. Antibiofilm and quorum sensing inhibitory potential of Cuminum cyminum and its secondary metabolite methyl eugenol against Gram negative bacterial pathogens. Food Res. Int. 2012, 45, 85-92. [CrossRef]

Sample Availability: Samples of the compounds essential oil of Cinnamomum camphora Leaf are available from the authors.

(C) 2019 by the authors. Licensee MDPI, Basel, Switzerland. This article is an open access article distributed under the terms and conditions of the Creative Commons Attribution (CC BY) license (http://creativecommons.org/licenses/by/4.0/). 